
Revue canadienne de chimie

\title{
Nanoscale Thin Films of Niobium Oxide on Platinum Surfaces: Creating a Platform for Optimizing Material Composition and Electrochemical Stability
}

\begin{tabular}{|r|l|}
\hline Journal: & Canadian Journal of Chemistry \\
\hline Manuscript ID & cjc-2017-0595.R1 \\
\hline Manuscript Type: & Article \\
\hline Date Submitted by the Author: & 09-Dec-2017 \\
\hline Complete List of Authors: & $\begin{array}{l}\text { Eastcott, Jennie; Simon Fraser University, Chemistry } \\
\text { Parakh, Abhinav; Simon Fraser University, Chemistry } \\
\text { Paul, Michael; Simon Fraser University, Chemistry } \\
\text { Lee, Austin; Simon Fraser University, Chemistry } \\
\text { Bilton, Matthew; Simon Fraser University, Chemistry } \\
\text { Gates, Byron; Simon Fraser University, Chemistry }\end{array}$ \\
\hline $\begin{array}{r}\text { Is the invited manuscript for } \\
\text { consideration in a Special } \\
\text { Issue?: }\end{array}$ & SFU \\
\hline Keyword: & $\begin{array}{l}\text { proton exchange membrane fuel cell, atomic layer deposition, niobium } \\
\text { oxide, platinum, degradation }\end{array}$ \\
\hline &
\end{tabular}


2 Nanoscale Thin Films of Niobium Oxide on Platinum Surfaces: Creating a Platform for Optimizing Material Composition and Electrochemical Stability 


\section{Abstract}

20 A nanoscale thin film of niobium oxide on a platinum substrate was evaluated for its influence on the

21 electronic and chemical properties of the underlying platinum towards the oxygen reduction reaction

22 with applications to proton exchange membrane fuel cells. The nanoscale thin film of niobium oxide was

23 deposited using atomic layer deposition onto the platinum substrate. A film of niobium oxide is a

24 chemically stable and electronically insulating material that can be used to prevent corrosion and

25 electrochemical degradation when layers are several nanometers thick. These layers can be insulating if

26 sufficiently thick, and may not be sufficient to protect the platinum from corrosion if too thin. An 3-nm

27 thin film of niobium oxide was fabricated on the platinum surface to determine its influence on the

28 electronic and chemical properties at the interface of these materials. The atomic layer deposition

29 process enabled a precise control over the material composition, structure, and layer thickness. The

30 niobium oxide film was evaluated using cyclic voltammetry and electrochemical impedance

31 spectroscopy to evaluate whether a balance could be found between the inhibition of platinum

32 degradation and electronic insulation of the platinum for use in proton exchange membrane fuel cells.

33 The 3-nm thin niobium oxide film was found to be sufficiently thin to permit electronic conductivity

34 while reducing the incidence of platinum dissolution.

36 Keywords: proton exchange membrane fuel cell, atomic layer deposition, niobium oxide, platinum,

37 degradation 


\section{Introduction}

To ensure competitiveness in the growing alternative energy sector for automotive applications,

41 the next generation of proton exchange membrane fuel cells (PEMFCs) must exhibit enhanced durability

42 under a variety of operating conditions. The U.S. Department of Energy (U.S. DOE) year 2020 durability

43 targets specify that membrane electrode assemblies (MEAs) designed for automotive applications must

44 be able to survive 5000 hours with cycling, as well as a start-up/shut down durability of 5000 cycles. $^{[1]}$

45 Typical PEMFC electrode layers consist of a carbon-supported platinum catalyst mixed with a proton-

46 conducting polymer (ionomer). To achieve high durability in harsh fuel cell operating conditions, new

47 catalyst, support, and ionomer materials must be investigated and an improved understanding of novel

48 catalyst-support interactions is necessary. Improved durability must come with an overall cost

49 reduction. ${ }^{[1]}$ The various strategies for mitigating the durability shortcomings required for U.S. DOE

compliant fuel cell operation each have their own benefits and challenges. For the cathode catalyst

51 layers, aspects of the catalyst layer structure, such as ionomer type, ionomer loading, porosity, and layer

52 thickness must be optimized to maintain conversion efficiency after modifying the catalyst/support 53 properties. ${ }^{[2]}$

The carbon support used for many commercial platinum catalysts is thermodynamically inclined

55 towards corrosion throughout the entire fuel cell operation voltage range. ${ }^{[3]}$ During start-up and shut down of the fuel cell, potentials up to $1.5 \mathrm{~V}$ are produced and the carbon support degradation is

57 accelerated ${ }^{[3]}$, leading to loss of platinum surface area and decreases to both hydrogen oxidation 58 reaction (HOR) and oxygen reduction reaction (ORR) reaction efficiencies. Robust alternatives to carbon 59 supports have been investigated to preserve prolonged functionality of the platinum catalyst. In recent 60 years, metal oxides such as $\mathrm{TiO}_{x}, \mathrm{WO}_{x}, \mathrm{SiO}_{\mathrm{x}}, \mathrm{NbO}_{\mathrm{x}}$, and $\mathrm{TaO}_{\mathrm{x}}(\mathrm{x} \leq 2)$ have been of interest as both 61 catalysts and catalyst supports due to their multitude of fabrication options (e.g., sol gel, ALD/CVD, 62 magnetron sputtering, mechanical mixing), variety of oxide states, and their robust nature for fuel cell 
environments. ${ }^{[3-7]}$ One of the difficulties with metal oxide use in a fuel cell environment is that changes

64 in structure and, in some cases, dissolution can occur during electrochemical cycling in acidic environments. ${ }^{[3]}$ Exposure to different oxidative or reductive environments can change the nature of the metal oxide species and impact characteristics such as catalytic function and durability. Niobium oxides

67 can exist as electronically conductive $\left(\mathrm{NbO}_{2}\right)$, insulating $\left(\mathrm{Nb}_{2} \mathrm{O}_{5}\right)$, and semi-conducting forms $\left(\mathrm{NbO}_{\mathrm{x}}\right)$, and

68 can change between these structures with electrochemical cycling in different $\mathrm{pH}$ environments. ${ }^{[8]}$ As

69 platinum is the typical ORR catalyst for fuel cell applications, it is imperative to characterize these 70 changes, as well as the influence of the presence of platinum catalyst, on supports such as niobium

71 oxides under the types of fuel cell voltage conditions experienced during operation through catalytic

72 cycling. Exploring changes in the surface characteristics of niobium oxides in the presence of platinum

73 during voltage cycling will lead to a better understanding of the role that niobium oxides can play and

74 can lead to an optimization of their use as support materials for fuel cell catalyst layers.

Niobium oxide has been investigated for applications such as solar cells ${ }^{[9,10]}$, batteries ${ }^{[9]}$, semiconductors/electronics ${ }^{[9,11]}$, catalysis $^{[9,12]}$, optics ${ }^{[13-15]}$, and as a coating for automotive ${ }^{[13]}$ and

77 biomedical devices for use in vivo. ${ }^{[9,16,17]}$ The robust chemical stability, dynamic optical properties, high

78 refractive index, and array of amorphous and crystalline phases for $\mathrm{Nb}_{2} \mathrm{O}_{5}$ make it a very popular 79 material to study. ${ }^{[13]}$ Niobium oxides are known to have strong metal-support interaction (SMSI) ${ }^{[18-20]}$ 80 properties and are, therefore, appealing candidates as platinum catalyst supports. Niobium oxides also 81 have a high corrosion resistance and are thermodynamically stable. ${ }^{[16,21]}$

83 different degrees of hydrophilicity depending on whether it is amorphous or one of 12 crystalline

84 morphologies $^{[9]}$, and this if coupled with a high affinity to platinum would help decrease the need for a 85 high surface area support. ${ }^{[3]}$ Additionally, stable oxide films could be employed as coatings for fuel cell 
catalysts to prevent mechanisms of platinum degradation. These oxide films would be required to be both porous and sufficiently thin so as to not disrupt electronic conductivity and gas permeability.

To date, there is limited research related to niobium oxides and their applicability to fuel cells. Rocha et al. ${ }^{[19]}$ determined that the addition of even small amounts of $\mathrm{Nb}_{2} \mathrm{O}_{5}$ to Pt catalysts for PEMFCs enhanced CO tolerance (up to 100 ppm CO in the hydrogen feed) due to very high SMSIs. Huang et al. ${ }^{[23]}$ found that mixed $\mathrm{Nb}-\mathrm{Ti}$ oxides can exhibit high electrical conductivity and electrochemical stability, lending itself to be a potentially suitable Pt support as it had a positive impact on ORR activity and fuel cell performance after accelerated durability cycling. Similar results were obtained by Chhina et al. ${ }^{[24]}$ regarding mixed $\mathrm{Nb}-\mathrm{Ti}$ oxide supports. Zhang et al. ${ }^{[22]}$ investigated growth of niobium oxide (as $\mathrm{NbO}_{2}$ )/carbon nanotube (CNT) supports for platinum fuel cell catalysts. No considerable loss of electrochemical surface area was evident after 10000 complete electrochemical cycles within the region of 0.6 to $1.1 \mathrm{~V}$ versus RHE. Though some losses in electrochemical surface area and ORR activity were observed when cycling over a wider voltage range ( 0.5 to $1.4 \mathrm{~V}$ versus $\mathrm{RHE}$ ), the degradation was less than for similar Pt/CNT electrodes lacking the $\mathrm{NbO}_{2}$ layer. Sasaki et al. ${ }^{[20]}$ deposited very small quantities of platinum on carbon-supported $\mathrm{NbO}_{2}$ or $\mathrm{Nb}_{2} \mathrm{O}_{5}$ particles, determining that while the $\mathrm{Pt} / \mathrm{NbO}_{2} / \mathrm{C}$ particles had a high mass activity and durability, the $\mathrm{Pt} / \mathrm{Nb}_{2} \mathrm{O}_{5} / \mathrm{C}$ was able to achieve similar mass activities to traditional Pt/C electrocatalysts.

The method of niobium oxide preparation can heavily influence the properties of the final product. Material stresses, crystallite grain size, purity, thicknesses, and crystalline state are imparted by the methods chosen for preparing films of niobium oxide. ${ }^{[9]}$ Films of $\mathrm{Nb}_{2} \mathrm{O}_{5}$ can be produced using a variety of techniques, which include: (i) sol ge ${ }^{[9,18,20,25,26]}$; (ii) magnetron sputtering ${ }^{[4,13]}$; and (iii) atomic layer deposition. ${ }^{[11,27,28]}$ Benefits of employing atomic layer deposition (ALD) include the precise control of material composition, structure, and layer thickness. The ALD process is a form of chemical vapour deposition that differs from traditional forms due to its ability to alternatively expose the desired 
110 substrate to more precise amounts of precursors through pulsing and cycling of volatile reagents. ${ }^{[11]}$ To

111 create a metal oxide layer, at least two precursors (e.g., a volatile metal species, and either oxygen or

112 ozone or water) are sequentially introduced into a reaction chamber that contained the substrate of

113 interest under partial vacuum. Each reactant is introduced for a specific period of time and the chamber

114 purged before introducing the subsequent reactant(s). This process is repeated for a series of cycles to

115 promote film growth on a timescale of fractions of an angstrom per cycle. This thin film growth

116 technique enables a precise control over the resulting thickness and composition. Atomic layer

117 deposition has been used for the fabrication of semiconductors and nanomaterials for numerous

118 applications since the layers produced can be conformal to the underlying substrate and are free of 119 pinhole defects. ${ }^{[11]}$

In this study, nanometer-thin films of $\mathrm{Nb}_{2} \mathrm{O}_{5}$ were constructed onto platinum supports using ALD

121 techniques with the goal of determining whether such thin niobium films can preserve platinum activity

122 during electrochemical cycling without greatly impeding electronic conductivity. Improved

123 understanding of this interface will drive development of materials with enhanced performance and 124 robustness while balancing material cost. The use of ALD facilitated growth of thin films on the order of 125 less than one angstrom per cycle in a well-controlled environment. To the best of our knowledge, 126 nanometer-thin films of niobia produced via ALD have not been used to resist catalyst or catalyst 127 support degradation for fuel cell environments. To fully characterize the interface between platinum 128 and niobia, we examined changes in surface properties of the two materials to understand the limits of 129 their conductive capabilities and electrochemical stability as suited to PEMFC applications.

130 Experimental

131 Fabrication of platinum substrate layer by physical vapor deposition 
132 Silicon wafers were used as substrates for the platinum electrodes, which were prepared by physical

133 vapor deposition (PVD) techniques. Silicon wafers used in these studies were four-inch, p-type, test134 grade, single-side-polished (100) silicon wafer with a resistivity of between 1 and $10 \Omega \cdot \mathrm{cm}$. These 135 substrates were purchased from 4D LABS at Simon Fraser University (SFU). The silicon wafers were 136 thoroughly cleaned in a Class 100 clean room with a sequence of acetone, isopropyl alcohol, and oxygen 137 plasma (Technics, PEII-A) at 280 mTorr and $300 \mathrm{~W}$ of plasma prior to PVD treatment. This cleaning 138 process was performed to remove organic residue from the surfaces of the polished silicon wafer for 139 improved adhesion of the deposited films during subsequent processing steps. Metal deposition was 140 performed using a physical vapor deposition system (Kurt J. Lesker PVD75) with the chamber pressure $141<2.00 \mathrm{E}-6$ Torr. An $~ 5-\mathrm{nm}$ thick chromium layer was deposited with thermal evaporation technique to 142 ensure sufficient adhesion between the silicon wafer and the platinum layer. The platinum layer was 143 deposited using electron beam assisted evaporation technique with a target thickness of $\sim 200 \mathrm{~nm}$. The 144 thickness of thin films during the deposition was monitored using a quartz microbalance (Sigma SQM145242 ) installed within the PVD system.

\section{Fabrication of $\mathrm{Nb}_{2} \mathrm{O}_{5}$ thin films by atomic layer deposition}

147 A nanoscale thin films of $\mathrm{Nb}_{2} \mathrm{O}_{5}$ was prepared via a thermally assisted ALD process using a Cambridge 148 NanoTech Fiji F200 in 4D LABS at SFU. Briefly, the set-up includes a sample chamber with a load lock that 149 moves substrates into the reaction chamber. The reaction chamber was placed under vacuum and 150 purged with high purity argon gas (99.999\%, Praxair). The Pt coated on the polished silicon substrates $151(\sim 2 \mathrm{~cm} \times 2 \mathrm{~cm})$ were loaded into the ALD chamber for a sequential reaction with 152 tert(butylimino)tris(diethylamido)niobium (Sigma Aldrich), or TBTDEN, and $\mathrm{H}_{2} \mathrm{O}$ as precursors. The 153 chamber and substrate temperatures were set to $250{ }^{\circ} \mathrm{C}$ and $65{ }^{\circ} \mathrm{C}$, respectively, and the pressure was 154 held at 0.0156 Torr in the main chamber. The TBTDEN and $\mathrm{H}_{2} \mathrm{O}$ precursors were each heated to $65{ }^{\circ} \mathrm{C}$ 
155

156

157

158

159

160

161

162

163

164

165

166

167

168

169

170

171

172

173

174

175

176

177

overnight prior to the deposition process. The argon carrier gas and argon plasma flow rates were set to $60 \mathrm{sccm}$ and $200 \mathrm{sccm}$, respectively. The TBTDEN was introduced into the chamber for $1 \mathrm{~s}$, followed by the introduction of argon gas for $0.5 \mathrm{~s}$. After 3 of these cycles, the $\mathrm{H}_{2} \mathrm{O}$ was introduced to the chamber for $0.06 \mathrm{~s}$ followed by a $0.5 \mathrm{~s}$ argon gas purge. This process was repeated for a total of 270 times to achieve the desired target thickness of 3 nanometers. After deposition, the samples were cooled to room temperature under an argon atmosphere. The growth rate for the $\mathrm{Nb}_{2} \mathrm{O}_{5}$ film was determined vide infra to be $0.1 \AA$ /cycle under these reaction conditions. A schematic of the process can be found in Fig. 1.

\section{Physical characterization}

\section{Focused ion beam/scanning electron microscopy}

To evaluate the thickness of the ALD films, a focused ion beam (FIB) lift-out procedure was performed on the sample targeted to contain a 3-nm thick $\mathrm{Nb}_{2} \mathrm{O}_{5}$ film. The FIB process used an FEI Helios DualBeam scanning electron microscope (FIB-SEM) located in 4D LABS at SFU. An 16-nm thick layer of carbon and a 20-nm thick layer of iridium were coated onto the sample using a Leica EM ACE600 highvacuum sputter coater (4D LABS). For subsequent STEM-EDS analysis, these layers allowed for adequate separation between the platinum substrate and the protective layer of platinum subsequently deposited using the gas injection system (GIS) within the FIB-SEM as necessary to assist with the sample lift-out procedure. An $\sim 10-\mu \mathrm{m}$ wide by $3-\mu \mathrm{m}$ deep cross-section, and a sample thickness of $\sim 2 \mu \mathrm{m}$, was milled in the FIB-SEM using a gallium ion-source. The sample was then attached to an Omniprobe copper lift-out grid, and further thinned by to $\sim 30 \mathrm{~nm}$ by milling with the gallium ion-source.

The composition of the $3 \mathrm{~nm} \mathrm{Nb} \mathrm{O}_{5}$ film was determined using energy dispersive $\mathrm{X}$-ray spectroscopy (EDS), acquired using a FEI Osiris S/TEM equipped with a Super-X EDS detector system located in 4D LABS at SFU. Measurements were taken at 450 000x magnification at $200 \mathrm{kV}$. 


\section{Electrochemical characterization}

179 Sufficiently thin layers of $\mathrm{Nb}_{2} \mathrm{O}_{5}$ may offer protection to platinum surfaces to make them less susceptible to platinum dissolution and Ostwald ripening. The $\mathrm{Nb}_{2} \mathrm{O}_{5}$ is, however, electrically insulating and will

181 impede the flow of electrons and reactants to reaction sites if the film is too thick. Electrochemical 182 potential cycling was used to evaluate the functionality of the $\mathrm{Nb}_{2} \mathrm{O}_{5}$ coating in an environment 183 representative of a fuel cell.

184 Electrochemical measurements were performed with a Biologics Potentiostat (Model SP-150) using a three-electrode set-up in $0.09 \mathrm{M} \mathrm{H}_{2} \mathrm{SO}_{4}$ (Fisher Scientific, ACS Grade) while holding the electrolyte at room temperature. The three electrodes included a carbon counter electrode, $\mathrm{Ag} / \mathrm{AgCl}$ reference 187 electrode ( $\mathrm{CH}$ Instruments, part no. $\mathrm{CHI} 111$ ), and the $\mathrm{Nb}_{2} \mathrm{O}_{5} / \mathrm{Pt}$ sample as the working electrode. Note that since the ALD process produces a conformal layer, all edges of the PVD substrate were coated with the $\mathrm{Nb}_{2} \mathrm{O}_{5}$ coating. A flat copper clip soldered to a copper wire was used to attach a portion of the working electrode devoid of $\mathrm{Nb}_{2} \mathrm{O}_{5}$ layer to the electrochemical circuit. A portion of the working electrode with an area of $\sim 1 \mathrm{~cm} \times \sim 2 \mathrm{~cm}$ was submerged in the electrolyte. After analysis, the submerged portion of the surface had changed colour and its exact area was measured for surface area normalization of the results. A platinum film prepared without the $\mathrm{Nb}_{2} \mathrm{O}_{5}$ coating was used for comparison. The electrochemical set-up is shown in Fig. 2.

Prior to electrochemical analysis, the system was purged with nitrogen gas (Praxair, 99.998\%) to displace dissolved oxygen. The cell was sealed to reduce the introduction of oxygen gas during the 197 experiment. To sufficiently evaluate the ability of $\mathrm{Nb}_{2} \mathrm{O}_{5}$ to protect the platinum surfaces from degradation, an accelerated stress test (AST) protocol was used to encompass a range of potential degradation mechanisms. All voltage reported are versus the reversible hydrogen electrode (RHE). To evaluate the ability of the $\mathrm{Nb}_{2} \mathrm{O}_{5}$ to prevent degradation in a wide range of fuel cell voltage conditions, a 
201 wider potential cycling range was used similar to those proposed by Pizzutilo et al. ${ }^{29}$ The samples were 202 subjected to cyclic voltammetry (CV) experiments, scanning in the region of $0 \mathrm{~V}$ to $1.25 \mathrm{~V}$ (versus RHE) at $203100 \mathrm{mV} / \mathrm{s}$ for 100 complete scans to condition the surfaces, followed by 10 complete scans in the same 204 potential range at $50 \mathrm{mV} / \mathrm{s}$ to determine the electrochemically active surface area (ECSA) at the 205 beginning of test (BOT). An average ECSA was calculated using the $8^{\text {th }}, 9^{\text {th }}$, and $10^{\text {th }}$ scans. Linear sweep 206 voltammetry (LSV) was performed at $5 \mathrm{mV} / \mathrm{s}$ and the current was recorded every $1 \mathrm{mV}$ from $1.1 \mathrm{~V}$ to 0.2 207 V (versus RHE). Three LSV scans were obtained after the initial CV scans, and LSV plots consist of the 208 average of these three scans. Electrochemical impedance spectroscopy (EIS) measurements were 209 collected at a DC bias potential of $0.4 \mathrm{~V}$ (versus RHE) across a frequency range from $100 \mathrm{kHz}$ to $0.1 \mathrm{~Hz}$. 210 The finite transmission-line model developed by Pickup et al. was used to analyze the EIS data. ${ }^{[30]}$ The

211 AST involved cycling the sample from $0 \mathrm{~V}$ to $1.3 \mathrm{~V}$ (versus RHE) at $200 \mathrm{mV} / \mathrm{s}$ for a total of 5000 cycles. 212 After every 1000 cycles, the ECSA, LSV, and EIS test protocols were implemented to monitor 213 degradation.

\section{Results and Discussion}

\section{Fabrication of platinum thin film}

217 The successful fabrication of the platinum thin film layer was confirmed using scanning profilometry.

218 The profile, shown in Fig. 3, suggests that the total thickness of the platinum layer is between 205 to 210 $219 \mathrm{~nm}$. The PVD process required ca. $5 \mathrm{~nm}$ of chromium as an adhesion layer for the subsequent deposition 220 of the ca. 200-nm thick platinum. This result suggests that the targeted metal thickness was achieved by 221 the PVD process.

\section{Fabrication of nanometer scale thin films of $\mathrm{Nb}_{2} \mathrm{O}_{5}$}


223 Atomic layer deposition can very finely control the deposition of a range of materials. It is capable of

224 achieving a uniform layer thickness down to a few angstroms. There is an inherent difficultly to evaluate

225 the thickness of the films prepared at this scale. Many techniques can have difficulty to resolve the

226 properties of a nanometer-thin layer from the properties of the substrate. Traditional methods of

227 verifying layer thickness, such as scanning electron microscopy and ellipsometry, were either unable to

228 recognize the existence of the layer or require advanced models to determine the precise thickness. Our

229 attempts to characterize the $\mathrm{Nb}_{2} \mathrm{O}_{5}$ layers with interferometry, ellipsometry, and high-resolution

230 transmission electron microscopy (TEM) were unsuccessful. The layers proved to be too thin in contrast

231 to the properties of the platinum substrate to accurately resolve the $\mathrm{Nb}_{2} \mathrm{O}_{5}$ by any of these methods.

232 The EDS spectrum from a section of the substrate covered with the niobium oxide layer is shown in Fig.

233 4. The niobium oxide layer is sufficiently thin that a strong contribution from the platinum layer is

234 evident. Layers of carbon, iridium, and platinum were successively deposited onto the sample and a thin

235 cross-section lifted out using FIB techniques to help resolve the nanometer-thin film of $\mathrm{Nb}_{2} \mathrm{O}_{5}$. Fig. 5 a to

$2365 \mathrm{~d}$ display individual elemental EDS maps acquired for the 3-nm $\mathrm{Nb}_{2} \mathrm{O}_{5}$ nanometer-thin film after

237 sampling by FIB assisted lift-out. Platinum (Fig. 5a) is visible as both the PVD substrate and as part of the

238 FIB sample preparation. Niobium appears visible in many regions (Fig. 5b), possibly due to the overlap of

239 the first $\mathrm{Nb}$ peak with the Pt peak (Fig. 4). The brightest region in Fig. $5 \mathrm{~b}$ is the actual $\mathrm{Nb}_{2} \mathrm{O}_{5}$ film. Oxygen

240 (Fig. 5c) appears in all regions, but a concentrated oxygen region in seen in Fig. $5 c$ in the same region as

241 niobium is detected in Fig. 5b, indicating the successful deposition of niobium oxide species. The iridium

242 band in Fig. $5 \mathrm{~d}$ is a product of the FIB sample preparation.

243 The combined elemental map is seen in Fig. 6 (a and b). A layer of $\mathrm{Nb}_{2} \mathrm{O}_{5}$ is visualized (red region)

244 between the PVD deposited platinum (green region) and FIB deposited carbon (black region) layers. The

245 thickness of the $\mathrm{Nb}_{2} \mathrm{O}_{5}$ layer was estimated to be $\sim 3-\mathrm{nm}$ from these results, which was the target 246 thickness for the sample. 
247 Electrochemical characterization

248 Results of electrochemical cycling are summarized in Table 1. As the samples were created via PVD and 249 did not contain platinum nanoparticles, a geometric surface area of the electrolyte-immersed electrode 250 surface was used for normalization of ECSA values. Exposure of each sample to the electrolyte and, thus, 251 the area to undergo electrochemical cycling was approximately $2 \mathrm{~cm} \times 1 \mathrm{~cm}$ (measurements to $0.01 \mathrm{~cm}$ 252 used for area calculation), plus the $200 \mathrm{~nm}$ thick edges. It is expected that no region of bare platinum is 253 exposed to the electrolyte for the $\mathrm{Nb}_{2} \mathrm{O}_{5}$-coated sample as the ALD process is conformal. The beginning 254 of test (BOT) cyclic voltammetry scans are shown in Fig. 7. The 3-nm $\mathrm{Nb}_{2} \mathrm{O}_{5}$ film does not appear to 255 considerably inhibit the electronic conductivity of the Pt layer. While the ECSA decreased for both 256 samples, the niobium oxide coated sample exhibited a higher retention of ECSA (26.5 $\pm 1.7 \%$ loss) 257 compared to the bare platinum film (33.7 $\pm 5.0 \%$ loss). Fig. 8 depicts LSV scans taken at BOT and EOT for 258 each sample. Both the bare Pt and $\mathrm{Nb}_{2} \mathrm{O}_{5}$-coated samples have almost identical LSV profiles between 2590.75 to $1.1 \mathrm{~V}$ vs RHE and almost the same value at $-0.03 \mathrm{~mA} / \mathrm{cm}^{2}(0.793 \mathrm{~V}$ and $0.784 \mathrm{~V}$, respectively). 260 After the AST protocol, at $-0.03 \mathrm{~mA} / \mathrm{cm}^{2}$ there is a $71 \mathrm{mV}$ shift in the onset potential for the bare Pt

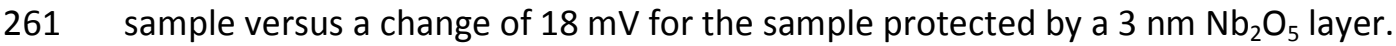

262 Electrochemical impedance spectroscopy (EIS) results have been summarized as Nyquist plots (Fig. 9a), 263 capacitance plots (Fig. 9b), and normalized capacitance plots (Fig. 9c). In Fig. 9, the steepness of the 264 slope for the bare Pt BOT compared to the niobia-coated sample indicates that the $\mathrm{Nb}_{2} \mathrm{O}_{5}$ film causes 265 some increase of electronic resistance. While the bare Pt EOT plot displays less resistance than either of 266 the coated samples, the increase in resistance after electrochemical cycling is greater for the bare Pt 267 sample than for the $\mathrm{Nb}_{2} \mathrm{O}_{5}$-coated sample. These differences are better visualized as capacitance plots in 268 Fig. 9b. The $\mathrm{Nb}_{2} \mathrm{O}_{5}$-coated sample has slightly lower capacitance than the bare Pt sample, but the change 
269 in capacitance over time is clearly much greater for the bare Pt sample. By normalizing these plots to 270 their maximum capacitance value (Fig. 9c), this difference is more easily noted.

271 The results described from Figs. 7 to 9 highlight that with prolonged electrochemical testing at the 272 applied potentials, there is less degradation when the sample had a passivation film of $\mathrm{Nb}_{2} \mathrm{O}_{5}$ despite 273 the materials insulating properties. The nanoscale coverage of the $\mathrm{Nb}_{2} \mathrm{O}_{5}$ layer did not induce a 274 noteworthy reduction in platinum accessibility or a detrimental increase in electrical resistance during 275 the electrochemical reaction, yet provides an enhanced chemical and electrochemical stability under 276 degradation conditions that would be experienced in fuel cell environments. Future development and 277 understanding of the interfaces created using ALD fabricated thin films can lead to intelligent design of 278 passivation layers to protect nanofabricated fuel cell catalyst layers from degradation.

\section{Conclusion}

281 In this paper, we have demonstrated the successful deposition of a nanometer-thin layer of $\mathrm{Nb}_{2} \mathrm{O}_{5}$ onto 282 platinum using atomic layer deposition to act as a passivation layer to platinum dissolution during 283 electrochemical cycling. $\mathrm{A} \mathrm{Nb}_{2} \mathrm{O}_{5}$ layer with a thicknesses of $3 \mathrm{~nm}$ has been achieved, and the layer has 284 been exposed to electrochemical cycling to evaluate resistance to platinum degradation conditions. The 285 thickness of the layer was verified using SEM-FIB. To our knowledge, nanometer-thin $\mathrm{Nb}_{2} \mathrm{O}_{5}$ protective 286 films produced to this nanometer scale have not been tested for their electrochemical stability to 287 protect platinum for fuel cell applications. With improved understanding of the limits to these 288 electronically conductive/electronically insulating interfaces, design and processing of fuel cell catalyst 289 materials can be improved to meet future performance and durability targets. 


\section{Acknowledgements}

292 The authors acknowledge financial support from Mitacs (Elevate Grant No. IT05186) in collaboration 293 with Automotive Fuel Cell Cooperation Corporation (J. Eastcott), the Mitacs Globalink Programs (A. 294 Parakh), the Natural Sciences and Engineering Research Council (NSERC) of Canada (Discovery Grant No. 295 1077758), the Canada Research Chairs Program (B.D. Gates, Grant No. 950-215846), and MNT Financial 296 Assistance (CMC Microsystems, Grant No. 4295). This work made use of the 4D LABS (www.4dlabs.ca) 297 and the Centre for Soft Materials shared facilities supported by the Canada Foundation for Innovation 298 (CFI), British Columbia Knowledge Development Fund (BCKDF), Western Economic Diversification 299 Canada, and Simon Fraser University. The authors gratefully acknowledge the 4D LABS staff for their 300 assistance and expertise related to this project.

\section{References}

303 (1) US Office of energy efficiency \& renewable energy. Fuel Cell Technol. Off. Multi-Year Res. Dev. Demonstr. Plan 2017, 3.4.1.

305 (2) Holdcroft, S. Chemistry of Materials. 2014, pp 381-393.

306 (3) Mench, M. M.; Kumbur, E. C.; Veziroglu, T. N.; Kocha, S. S. In Polymer Electrolyte Fuel Cell Degradation; 2012; pp 89-214.

308 (4) Zhang, L.; Wang, L.; Holt, C. M. B.; Navessin, T.; Malek, K.; Eikerling, M. H.; Mitlin, D. J. Phys. Chem. C 2010, 114 (39), 16463.

310 (5) Takenaka, S.; Mikami, D.; Tanabe, E.; Matsune, H.; Kishida, M. Appl. Catal. A Gen. 2015, 492, 60.

311 (6) Takabatake, Y.; Noda, Z.; Lyth, S. M.; Hayashi, A.; Sasaki, K. Int. J. Hydrogen Energy 2014, 39, 
5074.

313 (7) Yan, L.; Rui, X.; Chen, G.; Xu, W.; Zou, G.; Luo, H. Nanoscale 2016, 8, 8843.

314 (8) Asselin, E.; Ahmed, T. M.; Alfantazi, A. Corros. Sci. 2007, 49 (2), 694.

315 (9) Aegerter, M. A. Sol. Energy Mater. Sol. Cells 2001, 68 (3-4), 401.

316 (10) Kim, H.-N.; Moon, J. H. ACS Appl. Mater. Interfaces 2012, 4 (11), 5821.

317 (11) Blanquart, T.; Niinistö, J.; Heikkilä, M.; Sajavaara, T.; Kukli, K.; Puukilainen, E.; Xu, C.; Hunks, W.;

(12) Ma, X.; Chen, Y.; Li, H.; Cui, X.; Lin, Y. Mater. Res. Bull. 2015, 66, 51.

320

(13) Graça, M. P. F.; Saraiva, M.; Freire, F. N. A.; Valente, M. A.; Costa, L. C. Thin Solid Films 2015, 585

321 (1), 95.

(14) Verma, A.; Singh, P. K. Indian J. Chem. - Sect. A Inorganic, Phys. Theor. Anal. Chem. 2013, 52 (5), 323 593.

(15) Sreethawong, T.; Ngamsinlapasathian, S.; Yoshikawa, S. Mater. Lett. 2012, 78, 135.

(16) Amaravathy, P.; Sowndarya, S.; Sathyanarayanan, S.; Rajendran, N. Surf. Coatings Technol. 2014, 244, 131.

(17) Velten, D.; Eisenbarth, E.; Schanne, N.; Breme, J. J. Mater. Sci. Mater. Med. 2004, 15 (4), 457.

(18) Orilall, M. C.; Matsumoto, F.; Zhou, Q.; Sai, H.; Abruña, H. D.; DiSalvo, F. J.; Wiesner, U. J. Am. Chem. Soc. 2009, 131 (26), 9389.

(19) Rocha, T. A.; Ibanhi, F.; Colmati, F.; Linares, J. J.; Paganin, V. A.; Gonzalez, E. R. J. Appl. Electrochem. 2013, 43 (8), 817. 
332 (20) Sasaki, K.; Zhang, L.; Adzic, R. R. Phys. Chem. Chem. Phys. 2008, 10 (1), 159.

333 (21) Varma, P. C. R.; Periyat, P.; Oubaha, M.; McDonagh, C.; Duffy, B. Surf. Coatings Technol. 2011, $334205(16), 3992$.

335 (22) Zhang, L.; Wang, L.; Holt, C. M. B.; Zahiri, B.; Li, Z.; Malek, K.; Navessin, T.; Eikerling, M. H.; Mitlin, 336 D. Energy Environ. Sci. 2012, 5 (3), 6156.

(23) Huang, S.-Y.; Ganesan, P.; Popov, B. N. Appl. Catal. B Environ. 2010, 96 (1-2), 224.

(24) Chhina, H.; Campbell, S.; Kesler, O. J. Electrochem. Soc. 2009, 156 (10), B1232.

339

(25) Graca, M. P. F.; Meireles, a; Nico, C.; Valente, M. a. J. Alloys Compd. 2013, 553, 177.

340

(26) Sreethawong, T.; Ngamsinlapasathian, S.; Lim, S. H.; Yoshikawa, S. Chem. Eng. J. 2013, 215-216,

341 322.

342

(27) Sabarirajan, D. C.; Vlahakis, J.; White, R. D.; Zenyuk, I. V. ECS Trans. 2016, 75 (14), 747.

343

(28) Huang, Y.; Xu, Y.; Ding, S.-J.; Lu, H.-L.; Sun, Q.-Q.; Zhang, D. W.; Chen, Z. Appl. Surf. Sci. 2011, 257

344 (16), 7305.

345

(29) Pizzutilo, E.; Geiger, S.; Grote, J.-P.; Mingers, A.; Mayrhofer, K. J. J.; Arenz, M.; Cherevko, S. J. Electrochem. Soc. 2016, 163 (14), 1510.

(30) Easton, E. B.; Pickup, P. G. Electrochim. Acta 2005, 50 (12), 2469. 
Table 1. Electrochemically active surface area (ECSA) before (BOT: beginning of test) and after (EOT: end of test) 5000 sequential scans of the applied potential for a bare platinum film and for platinum films covered with 3-nm thick $\mathrm{Nb}_{2} \mathrm{O}_{5}$ film.

360

\begin{tabular}{ccccc}
\hline sample & $\begin{array}{c}\text { geometric surface } \\
\text { area }\left(\mathrm{cm}^{2}\right)\end{array}$ & $\begin{array}{c}\text { BOT ECSA } \\
\left(\mathrm{m}^{2} / \mathrm{g}\right)\end{array}$ & $\begin{array}{c}\text { EOT ECSA } \\
\left(\mathrm{m}^{2} / \mathrm{g}\right)\end{array}$ & $\begin{array}{c}\text { decrease in ECSA } \\
\text { with cycling (\%) }\end{array}$ \\
\hline bare Pt & 1.8 & $0.719 \pm 0.054$ & $0.475 \pm 0.004$ & $33.7 \pm 5.0$ \\
$\mathrm{Pt}+3 \mathrm{~nm} \mathrm{Nb}_{2} \mathrm{O}_{5}$ & 2 & $0.669 \pm 0.006$ & $0.492 \pm 0.008$ & $26.5 \pm 1.7$ \\
\hline
\end{tabular}

\section{Figure Captions}

Fig. 1. The atomic layer deposition (ALD) process for thin film deposition: a silicon wafer with a thin Pt chamber to grow a thin film of $\mathrm{Nb}_{2} \mathrm{O}_{5}(\sim 3 \mathrm{~nm})$. 
372 Fig. 3. Profilometry of the thin metal film consisting of a ca. 200-nm thick platinum layer deposited on an

$373 \sim 5-n m$ thick chromium adhesion layer supported on a polished silicon wafer.

374

375 Fig. 4. A representative energy dispersive X-ray spectroscopy (EDS) based spectrum for the 3-nm thick 376 niobium oxide film on a Pt layer.

Fig. 5. Individual EDS maps obtained in conjunction with high resolution TEM analyses of (a) platinum, (b) niobium, (c) oxygen, and (d) iridium for a cross section of the $\sim 3-n m$ thick films of supported $\mathrm{Nb}_{2} \mathrm{O}_{5}$. The scale bar in each image has a length of $10 \mathrm{~nm}$.

Fig. 6. Overlapping high resolution EDS maps at (a) $450000 x$ magnification and (b) $900000 x$ magnification of the $\sim 3-\mathrm{nm}$ thick $\mathrm{Nb}_{2} \mathrm{O}_{5}$ coating on a platinum substrate, which was prepared by a FIB

384 lift-out process. Black region = carbon layer. The scale bars for (a) and (b) are 20 and $10 \mathrm{~nm}$, 385 respectively.

387 Fig. 7. The initial cyclic voltammetry (CV) scans of the bare Pt prepared by physical vapour deposition or 388 PVD (black solid line) and the Pt PVD (red dashed line) coated with a 3-nm thick $\mathrm{Nb}_{2} \mathrm{O}_{5}$ layer. These 389 studies were performed at a scan rate of $50 \mathrm{mV} \mathrm{s}^{-1}$.

391 Fig 8. Linear sweep voltammetry (LSV) for bare Pt PVD samples (black lines) and the Pt PVD coated with 392 a 3-nm thick $\mathrm{Nb}_{2} \mathrm{O}_{5}$ layer (red lines) at BOT (solid line) and EOT (dotted line). These studies were 393 performed at a scan rate of $5 \mathrm{mV} \mathrm{s}^{-1}$. 
395 Fig 9. Electrochemical impedance spectroscopy (EIS) plots for bare Pt PVD samples (black lines; solid 396 symbols) and the 3-nm Nb${ }_{2} \mathrm{O}_{5}$ layer (red lines; open symbols) at BOT (solid line) and EOT (dotted line).

397 Plots include (a) Nyquist plot, (b) capacitance plot, and (c) normalized capacitance plot. 
1. prepare platinum thin film on a silicon wafer via PVD system

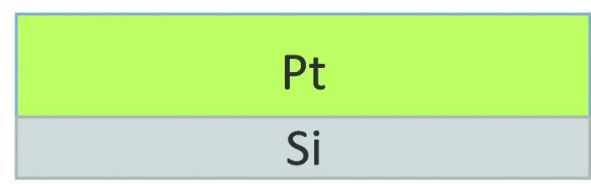

2. introduce TBTDEN to substrate via ALD system TBTDEN

\section{$\mathrm{Pt}$ \\ $\mathrm{Si}$}

3. introduce $\mathrm{H}_{2} \mathrm{O}$ to TBTDEN via ALD

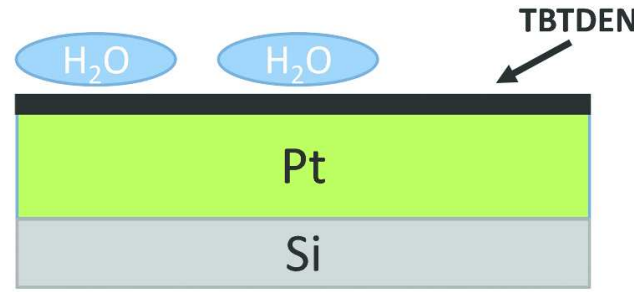

4. thermal ALD reaction to prepare nanometer thin $\mathrm{Nb}_{2} \mathrm{O}_{5}$ film

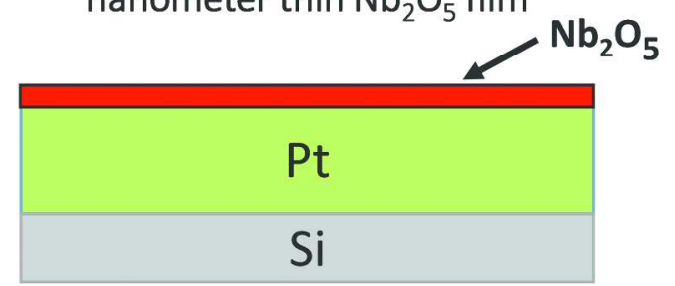

Figure 1

$190 \times 438 \mathrm{~mm}(300 \times 300$ DPI $)$ 


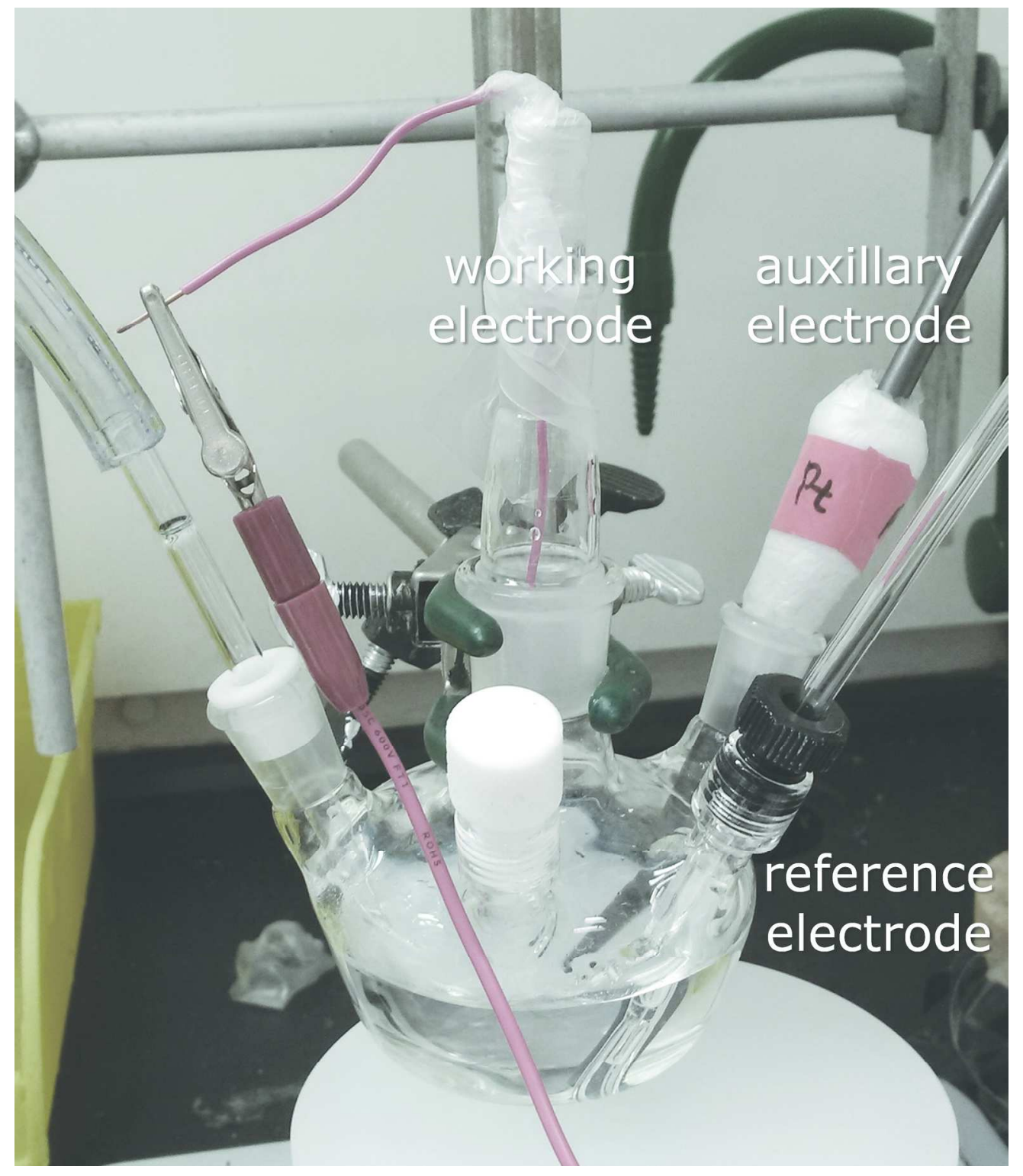

Figure 2

$96 \times 112 \mathrm{~mm}(600 \times 600 \mathrm{DPI})$ 


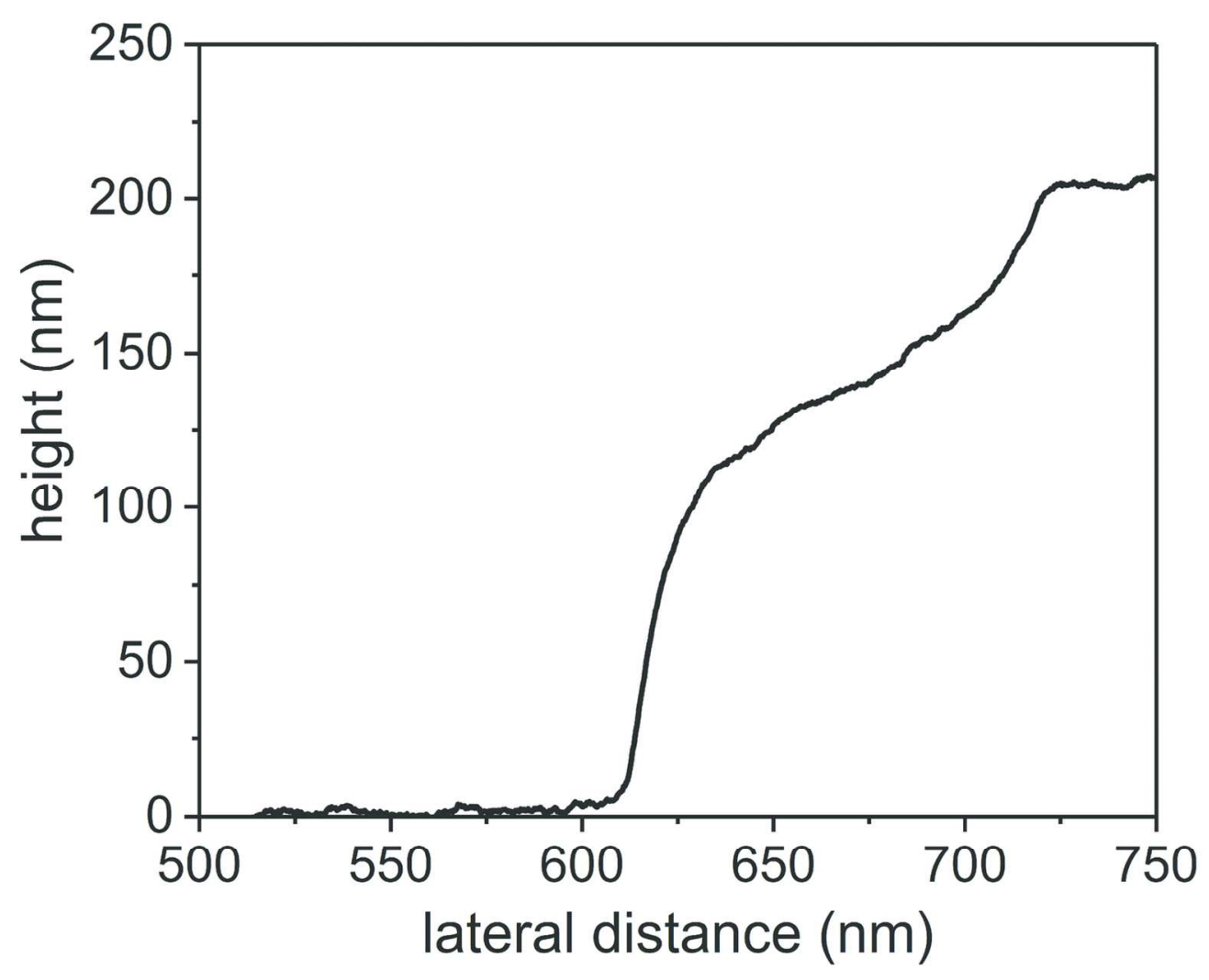

Figure 3

$65 \times 52 \mathrm{~mm}(600 \times 600 \mathrm{DPI})$ 


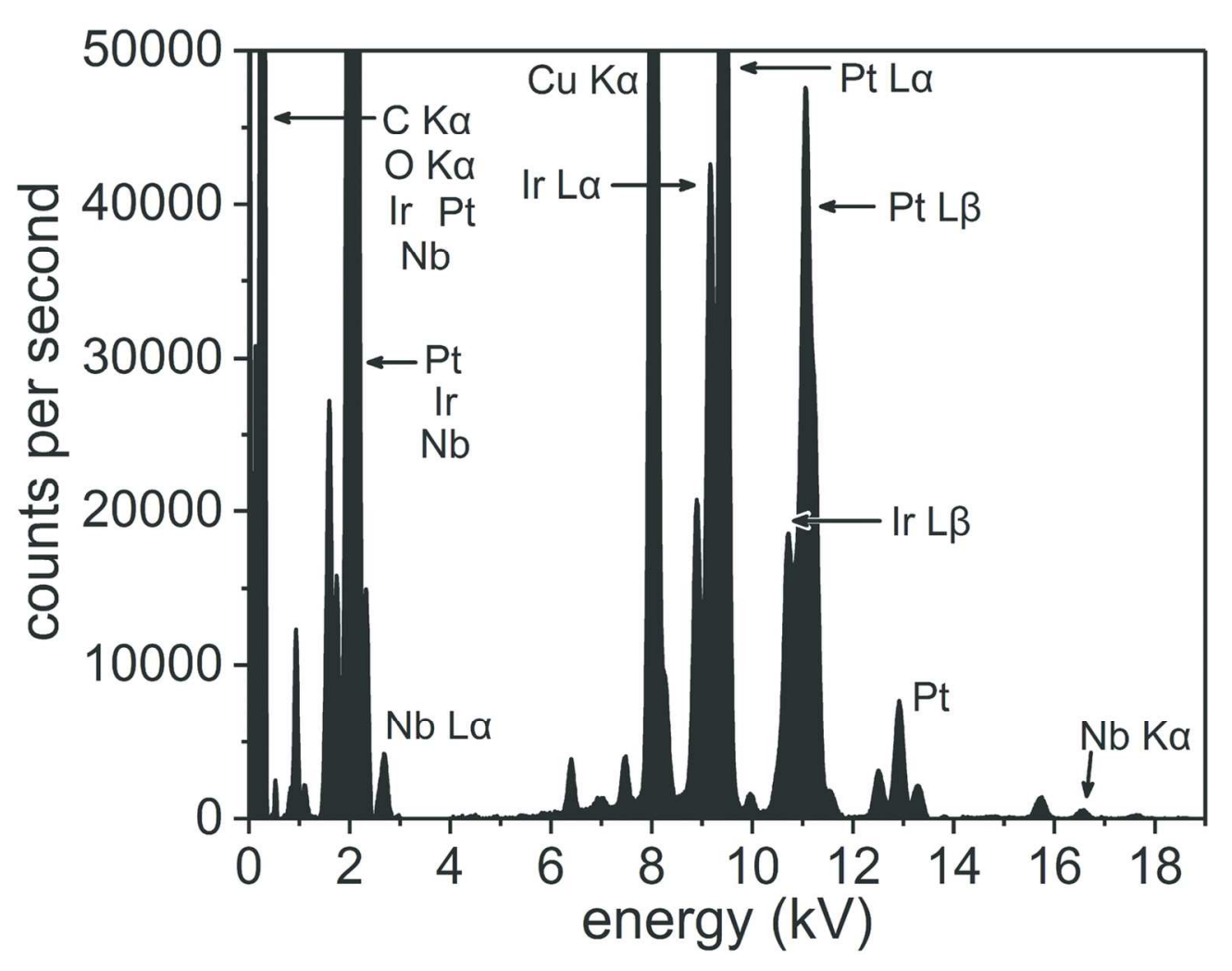

Figure 4

$64 \times 49 \mathrm{~mm}(600 \times 600 \mathrm{DPI})$ 

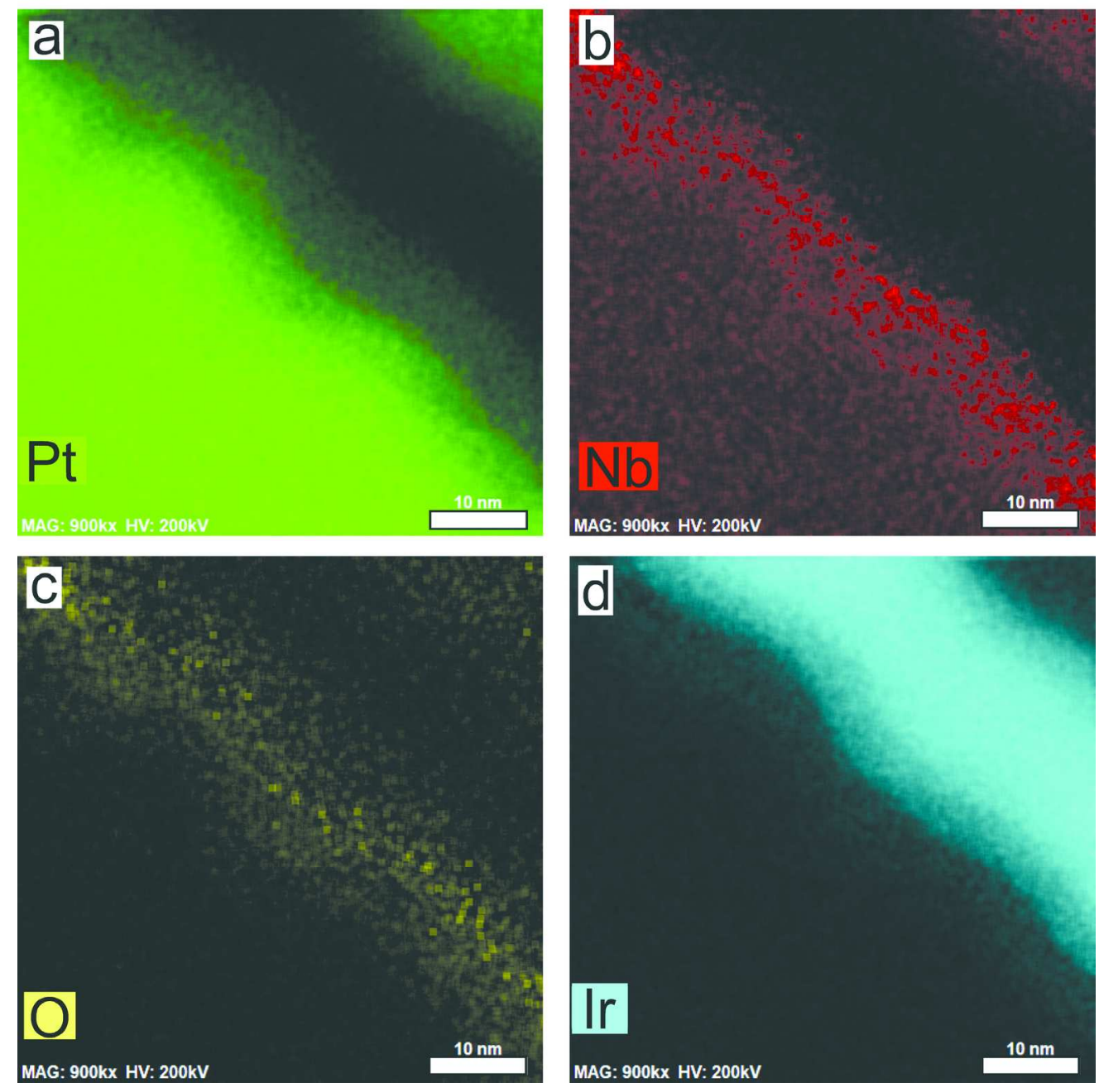

Figure 5

$166 \times 166 \mathrm{~mm}$ ( $300 \times 300$ DPI) 


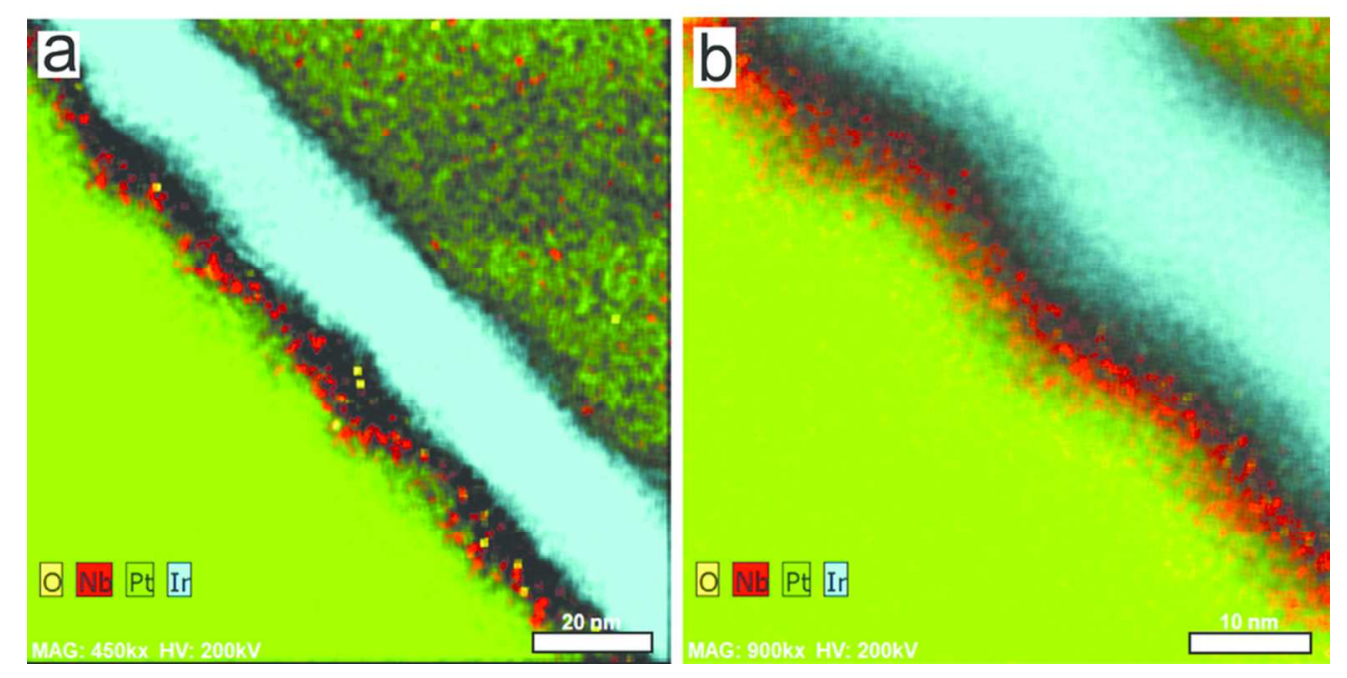

Figure 6

$83 \times 42 \mathrm{~mm}(300 \times 300$ DPI $)$ 


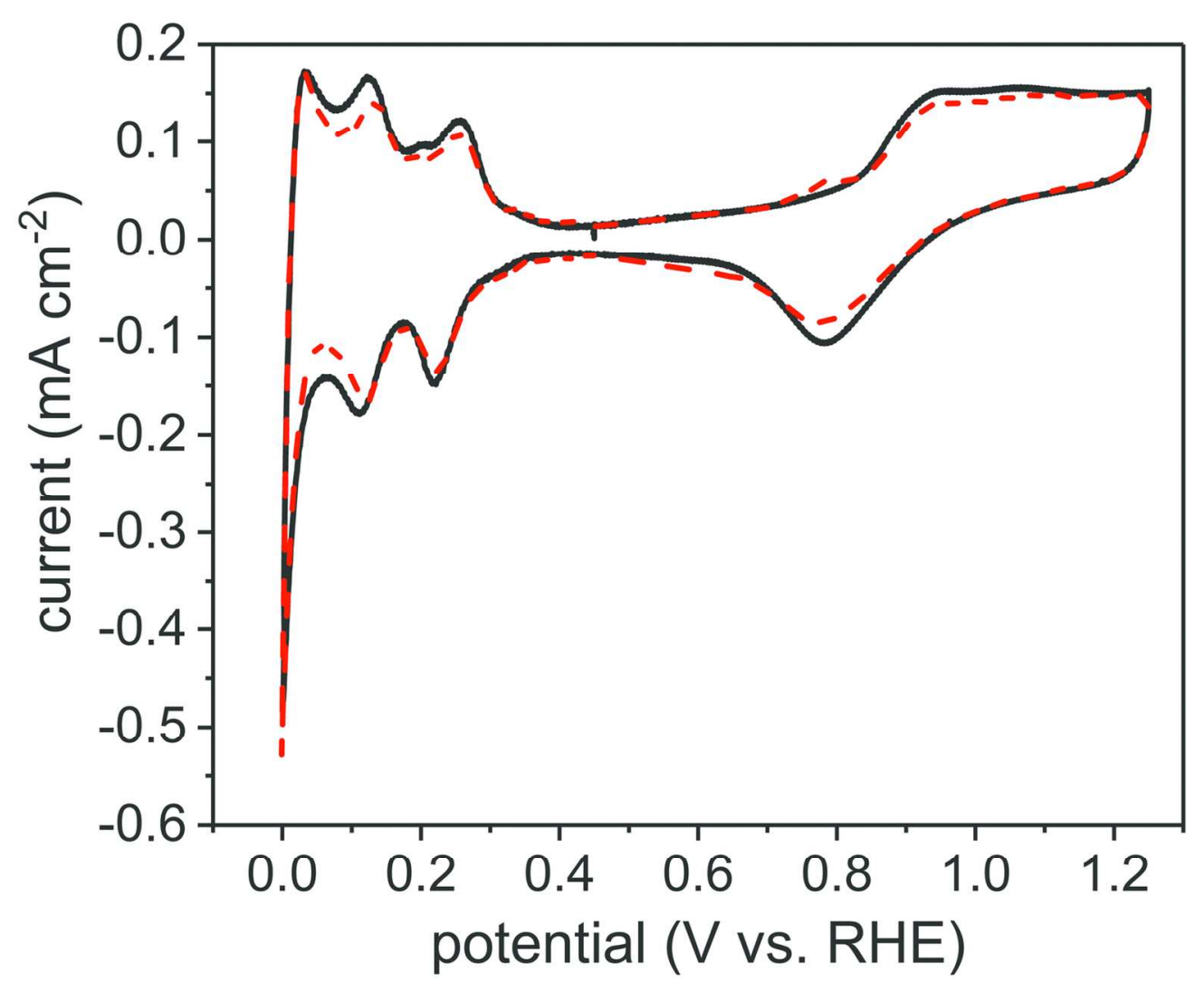

Figure 7

$67 \times 55 \mathrm{~mm}(600 \times 600 \mathrm{DPI})$ 


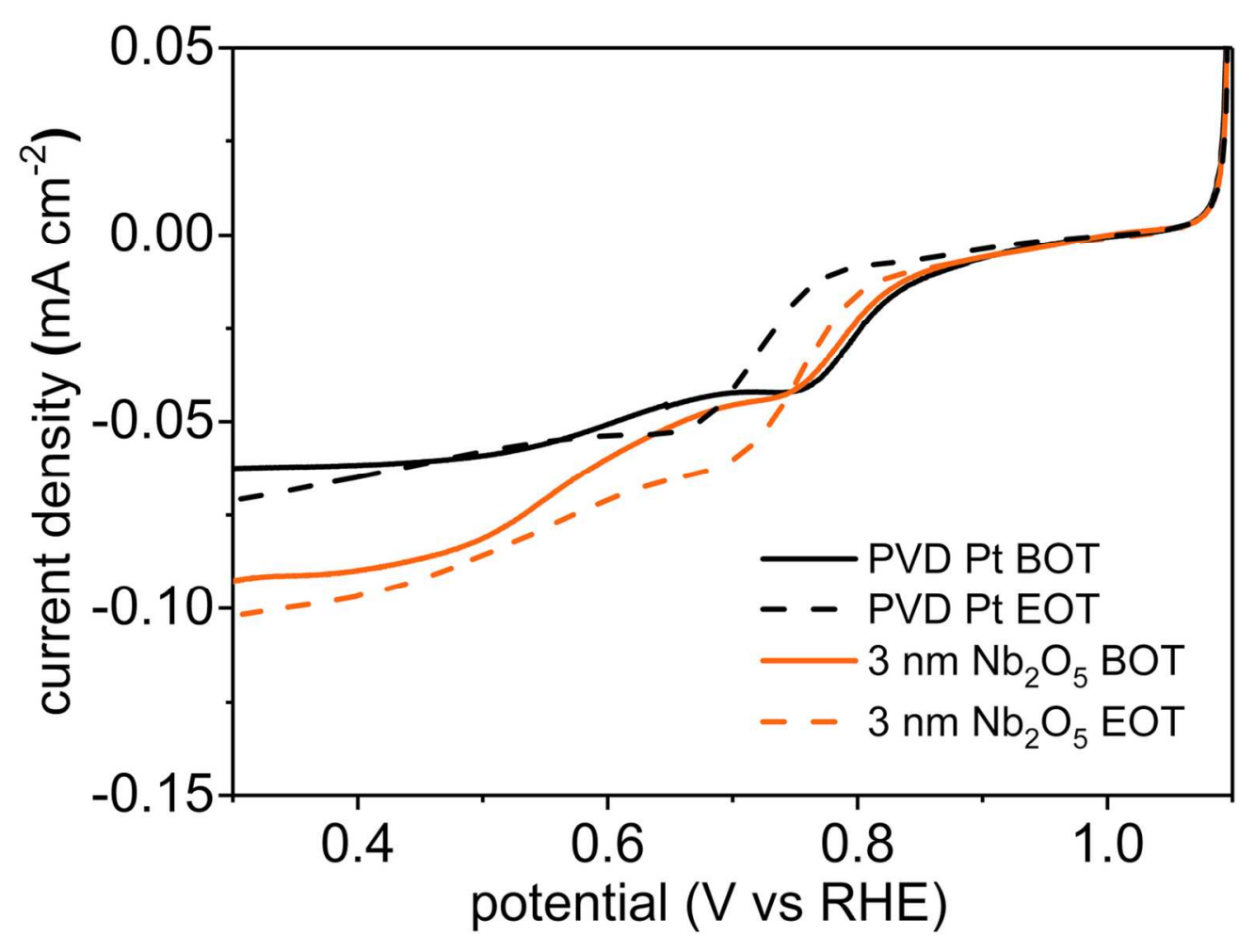

Figure 8

$62 \times 46 \mathrm{~mm}(600 \times 600 \mathrm{DPI})$ 

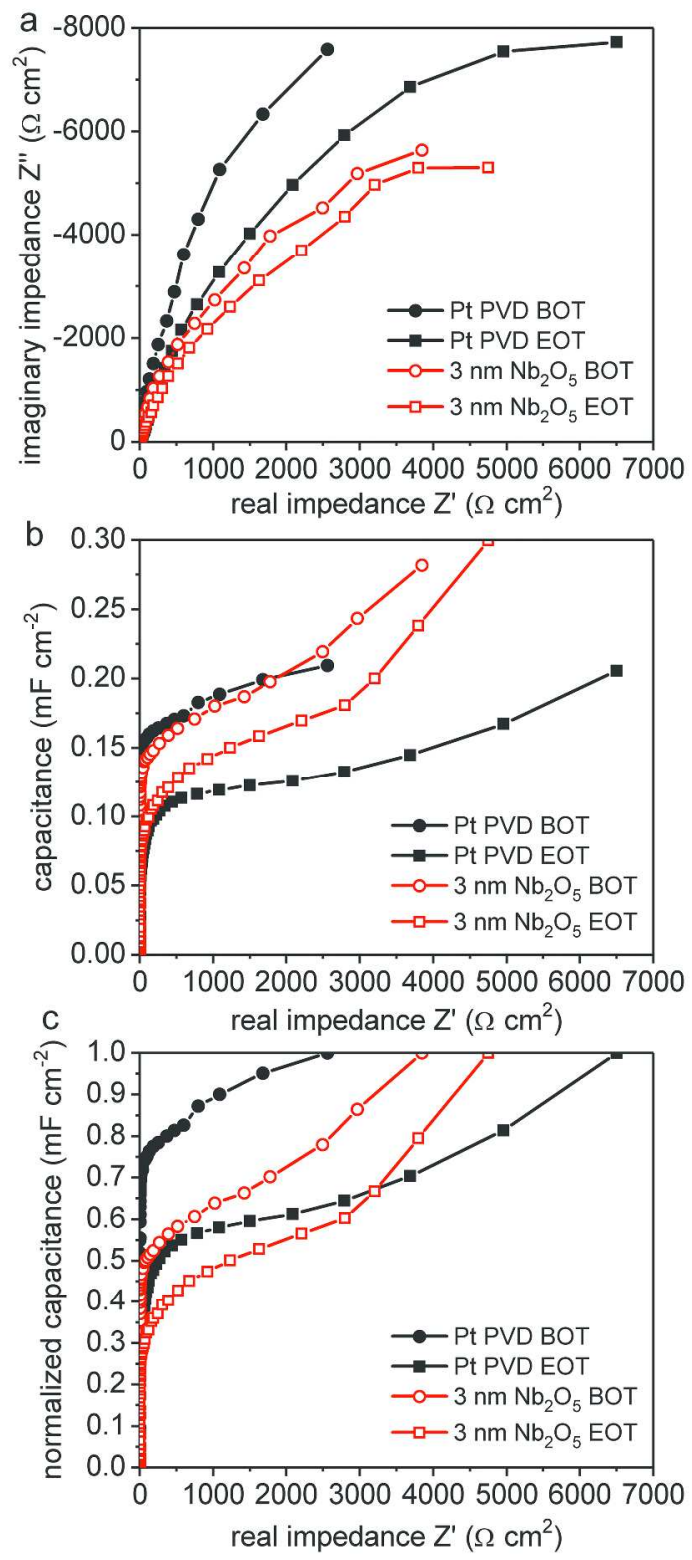

Figure 9

$187 \times 424 \mathrm{~mm}(600 \times 600 \mathrm{DPI})$ 